\title{
Faecal Calprotectin in Assessment of Mucosal Healing in Adults with Inflammatory Bowel Disease: A Meta-Analysis
}

\author{
Mariusz A. Bromke ${ }^{1, *(D)}$, Katarzyna Neubauer ${ }^{2} \mathbb{D}$, Radosław Kempiński ${ }^{2}$ (D) and Małgorzata Krzystek-Korpacka ${ }^{1}$ \\ 1 Department of Biochemistry and Immunochemistry, Wroclaw Medical University, Chalubinskiego 10, \\ 50-368 Wroclaw, Poland; malgorzata.krzystek-korpacka@umed.wroc.pl \\ 2 Department of Gastroenterology and Hepatology, Wroclaw Medical University, Borowska 213, \\ 50-556 Wroclaw, Poland; katarzyna.neubauer@umed.wroc.pl (K.N.); \\ radoslaw.kempinski@umed.wroc.pl (R.K.) \\ * Correspondence: mariusz.bromke@umed.wroc.pl
}

check for updates

Citation: Bromke, M.A.; Neubauer K.; Kempiński, R.;

Krzystek-Korpacka, M. Faecal Calprotectin in Assessment of Mucosal Healing in Adults with Inflammatory Bowel Disease: A Meta-Analysis. J. Clin. Med. 2021, 10, 2203. https://doi.org/10.3390/ jcm10102203

Academic Editor: Lorenzo Bertani

Received: 1 April 2021

Accepted: 15 May 2021

Published: 19 May 2021

Publisher's Note: MDPI stays neutral with regard to jurisdictional claims in published maps and institutional affiliations.

Copyright: (c) 2021 by the authors. Licensee MDPI, Basel, Switzerland. This article is an open access article distributed under the terms and conditions of the Creative Commons Attribution (CC BY) license (https:// creativecommons.org/licenses/by/ $4.0 /)$.

\begin{abstract}
Achieving mucosal healing in patients with inflammatory bowel disease is related to a higher incidence of sustained clinical remission and it translates to lower rates of hospitalisation and surgery. The assessment methods of disease activity and response to therapy are limited and mainly rely on colonoscopy. This meta-analysis reviews the effectiveness of using faecal calprotectin as a marker for mucosal healing in inflammatory bowel disease. Two meta-analyses were conducted in parallel. The analysis on the use of faecal calprotectin in monitoring mucosal healing in colonic Crohn's disease is based on 16 publications (17 studies). The data set for diagnostic values of faecal calprotectin in ulcerative colitis is composed of 35 original publications (total 49 studies). The DOR for the use of faecal calprotectin in Crohn's disease is estimated to be 11.20 and the area under the sROCis 0.829 . In cases of ulcerative colitis, the DOR is 14.48 , while the AUC sROC is 0.858 . Heterogeneity of the studies was moderatetosubstantial. Collected data show overall good sensitivity and specificity of the faecal calprotectin test, as well as a good DOR. Thus, monitoring of mucosal healing with a non-invasive faecal calprotectin test may represent an attractive option for physicians and patients with inflammatory bowel disease.
\end{abstract}

Keywords: inflammatory bowel disease; mucosal healing; faecal calprotectin; diagnostics; meta-analysis

\section{Introduction}

Inflammatory bowel disease (IBD) is an umbrella term for ulcerative colitis (UC) and Crohn's disease (CD), which are lifelong, severe conditions of the gastrointestinal tract, characterized by heterogeneous clinical presentation, a relapsing-remitting course and a wide spectrum of complications including extraintestinal manifestations [1-3].

Because of the complex and unclear pathogenesis of IBD, an effective causative treatment strategy of the disease is still missing. This, in turn, intensifies clinical trials not only of novel therapeutic agents, but also on therapeutic goals-especially important, considering the chronic and unpredictable course of IBD. A treat-to-target strategy aims to limit IBD progression and improve outcomes by adjusting therapy according to the achievement of predefined treatment response targets. The STRIDE (Selecting Therapeutic Targets in Inflammatory Bowel Disease) program identified the therapeutic targets for both UC and CD, as clinical/patient-reported outcome (PRO) remission and endoscopic remission. In addition, for $C D$, the resolution of inflammation-related findings on imaging in patients who cannot be adequately assessed with ileocolonoscopy $[4,5]$. The concept of deep remission (DR) is complex, and a standardised definition of DR is still missing [6]. Deep remission in UC refers to complete disease quiescence regarding endoscopic activity, rectal bleeding, and bowel movement [7].

Identification of mucosal healing $(\mathrm{MH})$ as a new therapeutic goal, different from clinical remission, has revolutionised the approach to IBD management. One weakness of 
MH is the need to use endoscopy for its evaluation, which is an invasive, time-consuming, and expensive technique. Moreover, there is no commonly accepted definition of $\mathrm{MH}$, although several scales or indices for objective classification of endoscopic findings have been devised. At the moment, the Mayo endoscopic score (MES) [8,9], is frequently usedin the evaluation of treatment efficacy in clinical trials, with MH defined as MES $\leq 1$. However, the guidelines of boththe European Crohn's and Colitis Organisationand the Japanese Society of Gastroenterologyrestrict complete endoscopic remission to a score of zero (normal or completely healed mucosa) [10-12]. The only two indices that received formal validation in UC, are the Ulcerative Colitis Endoscopic Index of Severity (UCEIS) and the Ulcerative Colitis Colonoscopic Index of Severity (UCCIS). In the UCEIS, an index value corresponding to endoscopic remission has not been defined, although $\mathrm{MH}$ is most often described as 0-1 point. Endoscopic activity of Crohn's disease may be reliably scored using either the Crohn's Disease Endoscopic Index of Severity (CDEIS) [13] or the Simple Endoscopic Score for Crohn's Disease (SES-CD) [14]. Both scales have been prospectively validated and are highly reproducible, with excellent inter-observer agreement.

Indeed, a catalogue of benefits associated with achieving MH in IBD justifies repeated endoscopic examinations, as it encompasses a more favorable course of the disease and is related to fewer surgeries and hospitalisations, as well as with a long-term clinical remission. For instance, mucosal healing in UC is accompanied by a lower risk of immunosuppression, colectomy, and colitis-associated neoplasia [15-18]. In turn, MH in CD is related with less severe inflammation after five years, decreased risk of future steroid treatment, and lower rates of surgical resection [5,19-21]. Successful control of intestinal inflammation may lead to improvement of extraintestinal manifestations of IBD, such as peripheral arthralgia [22], as well as relief in IBD-concomitant anxiety, depression, fatigue, and sleep disturbances [23]. Therefore, endoscopy, which together with pathological examination, serves as the key diagnostic tool in IBD, is further found useful in the monitoring of the disease activity. As mentioned before, endoscopy for $\mathrm{MH}$ evaluation is an invasive, time-consuming, and expensive technique. Non-invasive diagnostic biomarkers, able to at least limit the number of endoscopies, are searched for intensively. The urgent requirement for non-invasive indices in IBD is additionally augmented by the recent global growth in IBD incidence rates [24]. Furthermore, the current COVID-19 pandemic highlighted the significance of non-invasive point-of-care tests, that may be integrated with telemedicine in IBD patient care [25-27].

From among numerous potential biomarkers which have been evaluated in IBD, only faecal calprotectin (FC) has the potential to serve as an indicator of IBD activity [28].

Calprotectin is a cytosolic protein which is present in high concentrations in human neutrophils. Lower concentrations are found in monocytes and reactive macrophages. It has antimicrobial activity, as it sequesters zinc ions, helping to outcompete bacteria and yeast for this element and thus limiting their growth. The release of calprotectin is most likely related with death of neutrophils at the site of inflammation [29]. In the context of IBD, calprotectin release in the intestine translates into elevated concentrations in stool. As such, FC can be regarded as a measure of neutrophil infiltration of the intestinal mucosa and a marker of the overall severity of gut inflammation.

Faecal calprotectin is stable for 4-7 days [30] and the sampling does not involve uncomfortable procedures. In addition to specialised diagnostic laboratory protocols for FC determination, there are tests designed for low throughput point-of-care analysis, as well as self-testingthat can be performed at home by a patient. The latter assay kits are supported by a mobile device application, which helps to read out, calculate and communicate the result to a physician. This could be a useful tool for disease monitoring, prediction of relapses and for therapy optimisation.

Therefore, we conducted this meta-analysis to answer the questions: what is the diagnostic accuracy of the FC test as a biomarker of mucosal healing in IBD, and could it be applied in disease monitoring as well as in the assessment of the effectiveness of an ongoing therapy. 


\section{Materials and Methods}

The search for studies on the use of faecal calprotectin as a biomarker of mucosal healing in ulcerative colitis and Crohn's disease utilised the following strategy: (faecal calprotectin) AND (mucosal healing). In each round, the latter term was replaced with one of the following: healing, endoscopy, colonoscopy, Crohn's disease, ulcerative colitis, IBD, or inflammatory bowel disease. Spelling variants were included. The publication dates were constrained to studies published between 1 January 2009 and 31 August 2020. The searched databases were PubMed and Scopus.

Query results were cross-searched and cleaned of duplicates. The selection process was composed of the following steps: title search, abstract screening, full text search, and eligible study data extraction. At each step, study selection was verified by a second investigator. The inclusion criteria were: original publication, publication in English language, mucosal healing was diagnosed according to specific standards (indices); studies provided sufficient data to reconstruct contingency matrices. Exclusion criteria were as follows: letters, editorials, comments, conference papers; paediatric or adolescent patients; non-IBD related; non-colonic Crohn's disease; studies performed on animals or tissue cultures; experimental studies.

We have extracted information from eligible studies based on the first author, year of publication, research object, definition of mucosal healing, population size, prevalence, cut-off values, FC measurement method, and true and false positives and negatives. In two cases authors were asked to rectify their data before being included in the data set (Table S1).

The analysis of data was performed with $\mathrm{R}$ (version 4.0.2, downloaded: 22 June 2020). The packages, meta (univariate random effects meta-analysis, funnel plots) and mada (sROC, bivariate effects analysis with Reitsma model) were used. The summary statistics (sensitivity, specificity, and DOR) were analysed by performing univariate analysis with the meta package. The "metabin" function was used to calculate the DOR from contingency tables with the inverse variance method for weights of individual studies. Forrest and funnel plots were generated with the meta package. The mada package for bivariate analysis was applied in the estimation of the sROC curve. For this purpose, the "reitsma" function was used; with correction for zero values in rows only. The function estimated variance components by the restricted maximum likelihood method. We calculated the pooled sensitivity, specificity, and diagnostic odds ratio with their 95\% CI. Statistical heterogeneity was assessed with Cochrane's Q statistic and Higgins' $I^{2}$ value.

\section{Results}

This study was performed and reported according to the statement on Preferred Reporting Items for Systematic Reviews and Meta-Analyses (PRISMA) [31]. More details are presented in the supplementary PRISMA Checklist (Table S2). The two literature databases contained 2305 unique records which fit the search strategy. This formed a title search pool from which 562 publications were selected for the abstract screening. Out of these, 106 were found eligible after the screening of abstracts. Of that number, 52 publications contained information required for the meta-analysis (Figure S1: data acquisition flow diagram). Eventually, data from 16 publications were included in the data set on the use of FC in Crohn's disease. The diagnostic test for FC in ulcerative colitis was described in 35 original publications. In several cases, more than one data set was extracted from a publication. This was the case for studies in which different mucosal healing definitions or different FC measurement kits were compared.

In Figure 1 the total effect sizes of all 17 applications are shown. The diagnostic OR of the random effect model is 13.8 (95\% CI, 9.1 to 20.9) and the $p$-value $<0.0001$. With the use of FC in the diagnosis of MH in Crohn's disease, the odds of apositive result among persons with the disease in remission is approximately 14 times higher than the odds for positive results among persons with still active disease. The Higgins' $I^{2}$ of all studies is $37 \%$, and the $p$-value of the Cochrane Q statistic is 0.07 , indicating that there is moderate heterogeneity. 


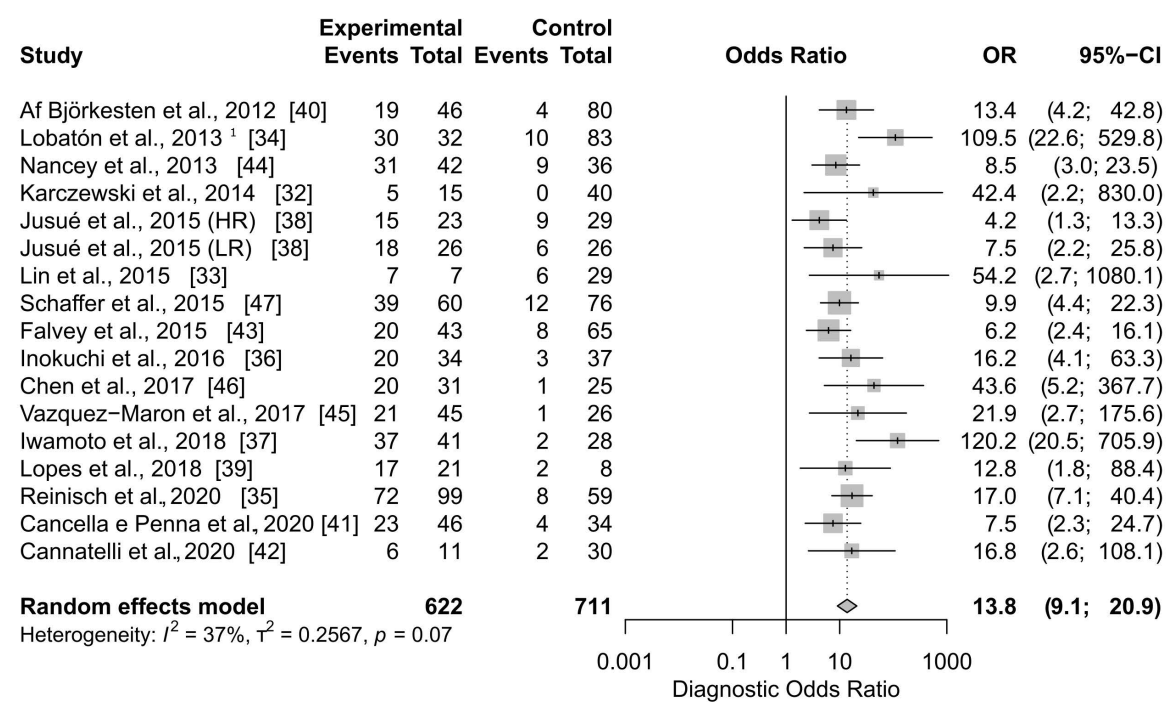

Figure 1. Forest plot of Diagnostic Odds Ratio calculated for the use of FC as the biomarker of mucosal healing in Crohn's disease. Abbreviations: CI, confidence interval; OR, odds ratio. Notes: Jusué et al. compared High Range (HR) and Low Range (LR) Quantum Blue rapid kits; ${ }^{1}$ ELISA test.

Table 1 shows the calculated sensitivity of the FC diagnostics of mucosal healing, with grouping according to the applied definition. The summary sensitivity with the random effect model is 0.828 (95\% CI, 0.769 to 0.874$)$. The Higgins' $I^{2}=51.7 \%$ and the Cochrane $Q$ statistic is 36.18 ( $p$-value $=0.0027)$ which suggest the existence of moderatetosubstantial heterogeneity. There is no significant difference in sensitivity between the SES-CD-based definitions of mucosal healing. The highest cumulative sensitivity was calculated for SES-CD $\leq 2$, that is 0.841 ( 5 studies). The summary specificity of 17 compared applications was estimated to be 0.759 (95\% CI, 0.683 to 0.821 ). The Higgins' $I^{2}=80.2 \%$ and the Cochrane Q statistic is 75.41 $(p$-value $<0.0001)$ which is indicative of substantial heterogeneity between the studies.

Figure 2 presents the sROC curve for the application of FC in the diagnosis of $\mathrm{MH}$ in Crohn's disease. The summary's AUC is 0.829 and the bivariate model-based estimation of $\mathrm{DOR}=11.20$.

To verify if there might be a publication bias, the DOR was plotted against the standard error of the effect estimate (data not shown). In the obtained funnel plot, three out of 17 included in this meta-analysis of applications of $\mathrm{FC}$ to diagnose $\mathrm{MH}$, are found outside of the 95\% ( $p$-value 0.05) boundaries. These were Jusué et al. [38] with a High Range test kit, Lobatón et al. [34], and Iwamoto et al. [37]. A tendency for a higher DOR in studies with a smaller tested population was observed.

Figure 3 shows DOR sizes of 49 applications of FC in the diagnosis of mucosal healing in ulcerative colitis. The summary diagnostic OR of the univariate random effect model is $16.0(95 \% \mathrm{CI}, 12.2$ to 21.1$)$ and the $p$-value $<0.0001$. The calculated cumulative OR for the use of FC in the diagnosis of MH in UC means that the odds of a positive result among persons with the disease in remission is 16 times higher than the odds for positive results among persons with still active inflammation. The Higgins' $I^{2}$ of all studies is $61 \%$, and the $p$-value of the Cochrane $Q$ statistic is $<0.0001$, indicating that there is moderatetosubstantial heterogeneity in the compared studies.

In Table 2, the FC diagnostic test sensitivity and specificity values in UC calculated from contingency matrix data are presented. The summary sensitivity with the univariate random effect model is $0.804(95 \% \mathrm{CI}, 0.757$ to 0.843$)$. The Higgins' $\mathrm{I}^{2}=87.5 \%$ and the Cochrane $Q$ statistic is 363.28 ( $p$-value $<0.0001$ ) which suggest the existence of substantial heterogeneity. The MES $=0$ as the definition of MH was applied in 24 studies for which the specificity was estimated to be $0.798(95 \%$ CI $0.743 ; 0.843)$. Eleven studies applied MES $\leq 1$ and for those studies the test's specificity was 0.766 (95\% CI $0.697 ; 0.823)$. The summary specificity of 49 compared applications of the FC was estimated to be 0.817 
(95\% CI, 0.780 to 0.848 ). The Higgins' $\mathrm{I}^{2}=78.6 \%$ and the Cochrane $Q$ statistic is 209.42 ( $p$-value $<0.0001)$, indicating substantial heterogeneity between the studies of FC in the detection of the mucosal healing.

Table 1. Diagnostic test sensitivity and specificity calculated for the use of FC as the biomarker of mucosal healing in Crohn's disease. Studies are grouped by the MH definition applied. Abbreviations: CDEIS, Crohn's Disease Endoscopic Index of Severity; CI, confidence interval; MH, mucosal healing; SES-CD, Simple Endoscopic Score for Crohn's Disease; Sens., sensitivity; Spec., specificity. Notes: Jusué et al. compared High Range (HR) and Low Range (LR) Quantum Blue rapid kits; ${ }^{1}$ ELISA test.

\begin{tabular}{|c|c|c|c|c|}
\hline Author, Year of Publication & Ref. & Sens. $(95 \%-C I)$ & Spec. $(95 \%-C I)$ & Mucosal Healing Definition \\
\hline Karczewski et al., 2014 & [32] & $1.000(0.478 ; 1.000)$ & $0.800(0.663 ; 0.900)$ & CDEIS $<3$ \\
\hline Lin et al., 2015 & [33] & $0.538(0.251 ; 0.808)$ & $1.000(0.852 ; 1.000)$ & CDEIS $<6$ \\
\hline Lobatón et al., $2013^{1}$ & [34] & $0.750(0.588 ; 0.873)$ & $0.973(0.907 ; 0.997)$ & CDEIS $\leq 3$ \\
\hline Reinischet al., 2020 & [35] & $0.900(0.812 ; 0.956)$ & $0.654(0.538 ; 0.758)$ & CDEIS $\leq 3$ \\
\hline Inokuchi et al., 2016 & [36] & $0.870(0.664 ; 0.972)$ & $0.708(0.559 ; 0.830)$ & $\mathrm{SES}-\mathrm{CD}=0$ \\
\hline Iwamoto et al., 2018 & [37] & $0.949(0.827 ; 0.994)$ & $0.867(0.693 ; 0.962)$ & SES-CD $=0$ \\
\hline Jusué et al., 2015 (HR) & [38] & $0.625(0.406 ; 0.812)$ & $0.714(0.513 ; 0.868)$ & $\mathrm{SES}-\mathrm{CD}=0$ \\
\hline Jusué et al., 2015 (LR) & [38] & $0.750(0.533 ; 0.902)$ & $0.714(0.513 ; 0.868)$ & SES-CD $=0$ \\
\hline Lopes et al., 2018 & [39] & $0.895(0.669 ; 0.987)$ & $0.600(0.262 ; 0.878)$ & $\mathrm{SES}-\mathrm{CD}=0$ \\
\hline Af Björkesten et al., 2012 & {$[40]$} & $0.826(0.612 ; 0.950)$ & $0.738(0.642 ; 0.820)$ & SES-CD $\leq 2$ \\
\hline Cancella e Penna et al., 2020 & [41] & $0.852(0.663 ; 0.958)$ & $0.566(0.423 ; 0.702)$ & SES-CD $\leq 2$ \\
\hline Cannatelli et al., 2020 & {$[42]$} & $0.750(0.349 ; 0.968)$ & $0.848(0.681 ; 0.949)$ & SES-CD $\leq 2$ \\
\hline Falvey et al., 2015 & [43] & $0.714(0.513 ; 0.868)$ & $0.713(0.600 ; 0.808)$ & SES-CD $\leq 2$ \\
\hline Nancey et al., 2013 & {$[44]$} & $0.775(0.615 ; 0.892)$ & $0.711(0.541 ; 0.846)$ & $\mathrm{SES}-\mathrm{CD} \leq \overline{2}$ \\
\hline Vazquez-Morón et al., 2017 & [45] & $0.955(0.772 ; 0.999)$ & $0.510(0.363 ; 0.656)$ & SES-CD $\leq 2$ \\
\hline Chen et al., 2017 & {$[46]$} & $0.952(0.762 ; 0.999)$ & $0.686(0.507 ; 0.831)$ & SES-CD $\leq 3$ \\
\hline Schaffer et al., 2015 & {$[47]$} & $0.765(0.625 ; 0.872)$ & $0.753(0.647 ; 0.840)$ & SES-CD $\leq 3$ \\
\hline Random effects model: & & $0.828(0.769 ; 0.874)$ & $0.759(0.683 ; 0.821)$ & \\
\hline \multirow[t]{3}{*}{ Quantifying heterogeneity: } & & & & \\
\hline & & $\begin{array}{c}\operatorname{tau}^{2}=0.2803 \\
I^{2}=51.7 \%\end{array}$ & $\begin{array}{c}\mathrm{tau}^{2}=0.4648 \\
I^{2}=80.2 \%\end{array}$ & \\
\hline & & $\mathrm{Q}=36.18(0.0027)$ & $\mathrm{Q}=75.41(<0.0001)$ & \\
\hline
\end{tabular}

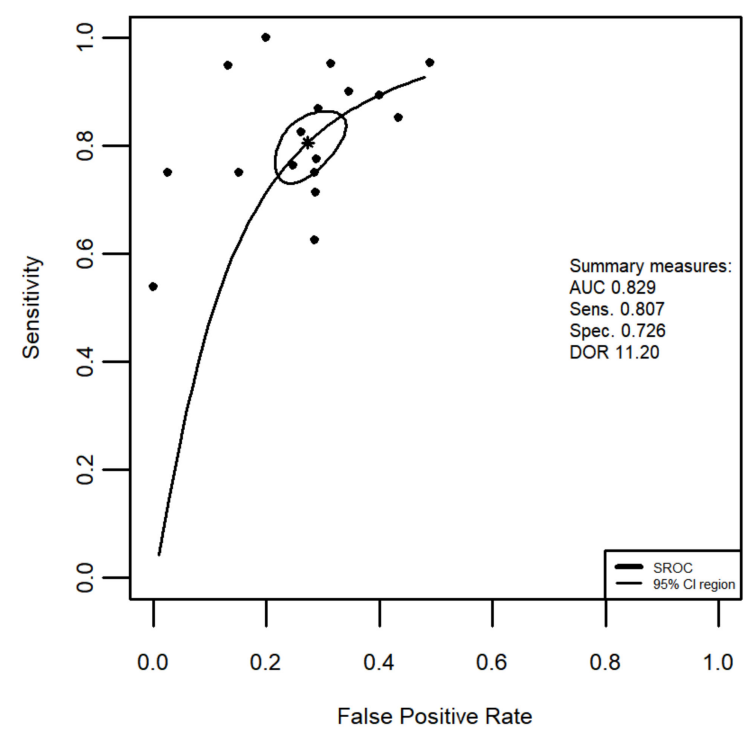

Figure 2. Summary Receiver Operating Characteristic (SROC) curve of the application of FC in the diagnosis of mucosal healing in Crohn's disease superimposed on Sensitivity and False Positive Rate (1-Specificity) results from 17 studies. Summary Sensitivity and summary False Positive Rate are shown as a star, with the $95 \%$ CI area circled. Abbreviations: AUC, area under the curve; Sens., sensitivity; Spec., specificity; DOR, diagnostic odds ratio, CI, confidence interval. 


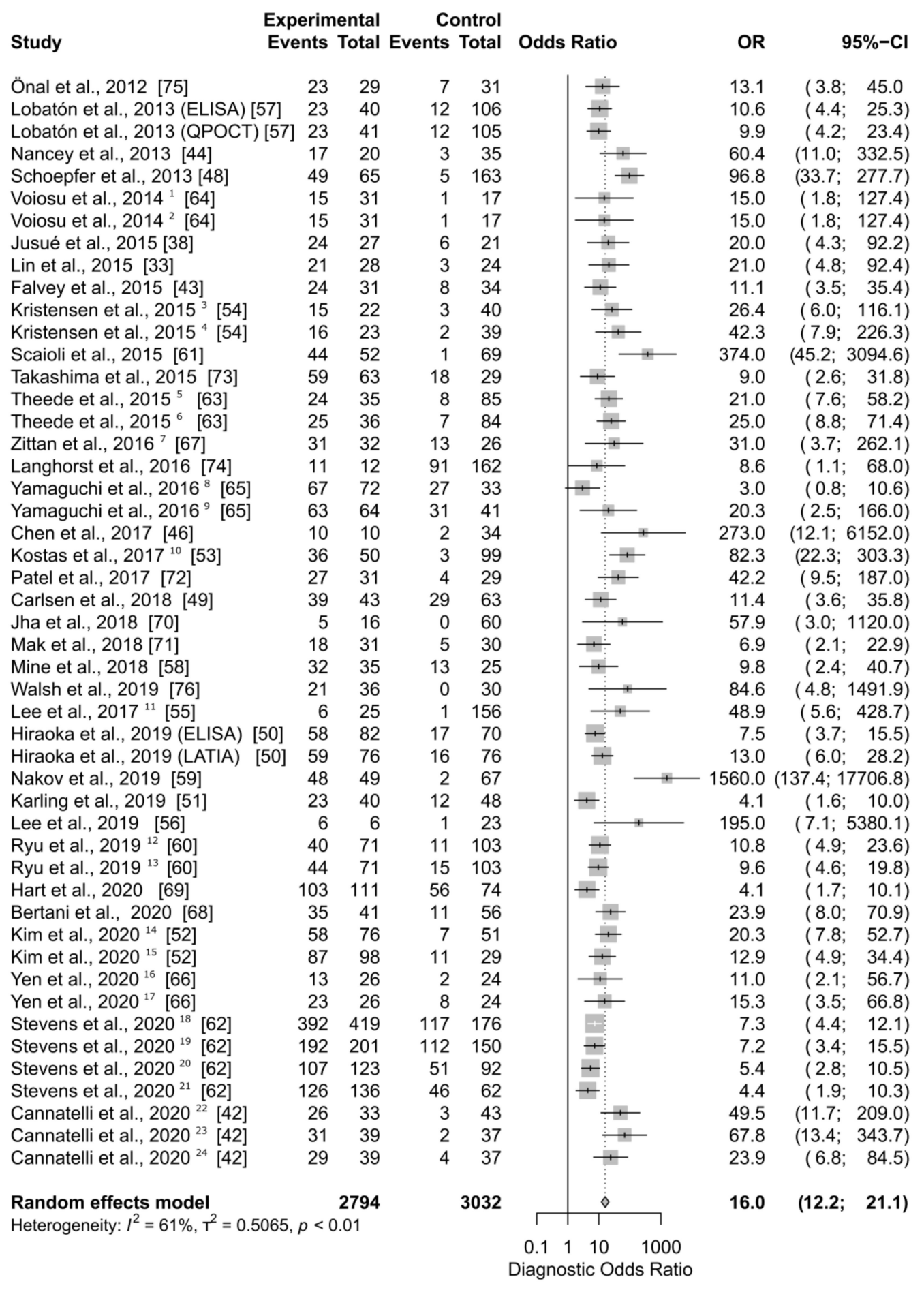

Figure 3. Forest plot of Diagnostic Odds Ratio calculated for the use of FC as the biomarker of mucosal healing in ulcerative colitis. Abbreviations: CI, confidence interval; OR, odds ratio. Notes: Hiraoka et al. compared ELISA and latex agglutination turbidimetric immunoassay (LATIA) kits; Lobatón et al. compared ELISA and Q-Point Of Care Test (QPOCT); Further indexed numbers mark different MH definitions: ${ }^{1}$ MES $=0 ;{ }^{2}$ SES-CD $\leq 3 ;{ }^{3}$ MES $=0 ;{ }^{4}$ MES $\leq 1 ;{ }^{5}$ MES $=0 ;{ }^{6}$ UCEIS $=0$; ${ }^{7} \mathrm{MES}=0 ;{ }^{8} \mathrm{MES}=0 ;{ }^{9} \mathrm{MES} \leq 1 ;{ }^{10} \mathrm{MES}=0 ;{ }^{11} \mathrm{MES}=0 ;{ }^{12} \mathrm{MES}=0 ;{ }^{13}$ UCEIS $\leq 1 . ;{ }^{14} \mathrm{MES}=0$; ${ }^{15}$ MES $\leq 1 ;{ }^{16}$ MES $=0 ;{ }^{17}$ MES $\leq 1 ;{ }^{18}$ MES $\leq 1$ (8 weeks of therapy); ${ }^{19}$ MES $\leq 1$ (52 weeks of therapy); ${ }^{20}$ MES $=0$ ( 8 weeks of therapy); ${ }^{21}$ MES $=0$ (52 weeks of therapy) $;{ }^{22}$ MES $=0,{ }^{23}$ UCEIS $\leq 1$; 24 modified PICaSSO $\leq 3$. 
Table 2. Diagnostic test sensitivity and specificity calculated for the use of FC as the biomarker of mucosal healing in ulcerative colitis. Studies are grouped by the MH definition applied. Abbreviations: CI, confidence interval; mBS, modified Baron Score; MES, Mayo endoscopic subscore; MH, mucosal healing; RI, Rachmilewitz Index; SES-CD, Simple Endoscopic Score for Ulcerative Colitis;Sens, sensitivity; Spec, specificity;UCEIS, Ulcerative Colitis Endoscopic Index of Severity. Notes: Stevens et al. compared diagnostic tests after 8 and 52 weeks of treatment (wk 8 andwk52, respectively). Hiraoka et al. compared ELISA and latex agglutination turbidimetric immunoassay (LATIA) kits; Lobatón et al. compared ELISA and Q-Point Of Care Tests (QPOCT).

\begin{tabular}{|c|c|c|c|c|}
\hline Author, Year of Publication & Ref. & Sens. $(95 \%-C I)$ & Spec. $(95 \%-C I)$ & Mucosal Healing Definition \\
\hline Falvey et al., 2015 & [43] & $0.750(0.566 ; 0.885)$ & $0.788(0.611 ; 0.910)$ & $\mathrm{mBS}=0$ \\
\hline Schoepfer et al., 2013 & [48] & $0.907(0.797 ; 0.969)$ & $0.908(0.855 ; 0.947)$ & $\mathrm{mBS} \leq 1$ \\
\hline Cannatelli et al., 2020 & {$[42]$} & $0.897(0.726 ; 0.978)$ & $0.851(0.717 ; 0.938)$ & MES $=0$ \\
\hline Carlsen et al., 2018 & [49] & $0.574(0.448 ; 0.693)$ & $0.895(0.752 ; 0.971)$ & $\mathrm{MES}=0$ \\
\hline Hiraoka et al., 2019 (ELISA) & {$[50]$} & $0.773(0.662 ; 0.862)$ & $0.688(0.573 ; 0.789)$ & $\mathrm{MES}=0$ \\
\hline Hiraoka et al., 2019 (LATIA) & {$[50]$} & 0.787 ( $0.677 ; 0.873)$ & $0.779(0.670 ; 0.866)$ & $\mathrm{MES}=0$ \\
\hline Jusué et al., 2015 & [38] & $0.800(0.614 ; 0.923)$ & $0.833(0.586 ; 0.964)$ & $\mathrm{MES}=0$ \\
\hline Karling et al., 2019 & [51] & $0.657(0.478 ; 0.809)$ & $0.679(0.537 ; 0.801)$ & $\mathrm{MES}=0$ \\
\hline Kim et al., 2020 & {$[52]$} & $0.892(0.791 ; 0.956)$ & $0.710(0.581 ; 0.818)$ & $\mathrm{MES}=0$ \\
\hline Kostas et al., 2017 & [53] & $0.923(0.791 ; 0.984)$ & $0.873(0.796 ; 0.929)$ & $\mathrm{MES}=0$ \\
\hline Kristensen et al., 2015 & {$[54]$} & $0.833(0.586 ; 0.964)$ & $0.841(0.699 ; 0.934)$ & $\mathrm{MES}=0$ \\
\hline Lee et al., 2017 & [55] & $0.857(0.421 ; 0.996)$ & $1.000(0.846 ; 1.000)$ & $\mathrm{MES}=0$ \\
\hline Lee et al., 2019 & {$[56]$} & $0.857(0.421 ; 0.996)$ & $0.891(0.835 ; 0.933)$ & $\mathrm{MES}=0$ \\
\hline Lobatón et al., 2013 (ELISA) & [57] & $0.657(0.478 ; 0.809)$ & $0.847(0.766 ; 0.908)$ & $\mathrm{MES}=0$ \\
\hline Lobatón et al., 2013 (QPOCT) & [57] & $0.657(0.478 ; 0.809)$ & $0.838(0.756 ; 0.901)$ & $\mathrm{MES}=0$ \\
\hline Mine et al., 2018 & {$[58]$} & $0.711(0.557 ; 0.836)$ & $0.800(0.519 ; 0.957)$ & $\mathrm{MES}=0$ \\
\hline Nakov et al., 2019 & {$[59]$} & $0.960(0.863 ; 0.995)$ & $0.985(0.918 ; 1.000)$ & $\mathrm{MES}=0$ \\
\hline Ryu et al., 2019 & [60] & 0.784 (0.647; 0.887$)$ & $0.748(0.662 ; 0.822)$ & $\mathrm{MES}=0$ \\
\hline Scaioli et al., 2015 & [61] & $0.978(0.882 ; 0.999)$ & $0.895(0.803 ; 0.953)$ & MES $=0$ \\
\hline Stevens et al., 2020 (wk 8) & {$[62]$} & $0.677(0.598 ; 0.749)$ & $0.719(0.585 ; 0.830)$ & $\mathrm{MES}=0$ \\
\hline Stevens et al., 2020 (wk 52) & [62] & $0.733(0.660 ; 0.797)$ & $0.615(0.406 ; 0.798)$ & $\mathrm{MES}=0$ \\
\hline Theede et al., 2015 & [63] & $0.750(0.566 ; 0.885)$ & $0.875(0.787 ; 0.936)$ & $\mathrm{MES}=0$ \\
\hline Voiosu et al., 2014 & [64] & $0.938(0.698 ; 0.998)$ & $0.500(0.319 ; 0.681)$ & MES $=0$ \\
\hline Yamaguchi et al., 2016 & [65] & $0.713(0.610 ; 0.801)$ & $0.545(0.234 ; 0.833)$ & $\mathrm{MES}=0$ \\
\hline Yen et al., 2020 & [66] & $0.867(0.595 ; 0.983)$ & $0.629(0.449 ; 0.785)$ & $\mathrm{MES}=0$ \\
\hline Zittan et al., 2016 & {$[67]$} & $0.705(0.548 ; 0.832)$ & $0.929(0.661 ; 0.998)$ & $\mathrm{MES}=0$ \\
\hline Bertani et al., 2020 & {$[68]$} & $0.761(0.612 ; 0.874)$ & $0.882(0.761 ; 0.956)$ & $\mathrm{MES} \leq 1$ \\
\hline Hart et al., 2020 & [69] & $0.648(0.568 ; 0.722)$ & $0.692(0.482 ; 0.857)$ & MES $\leq 1$ \\
\hline Jha et al., 2018 & [70] & $1.000(0.478 ; 1.000)$ & $0.845(0.740 ; 0.920)$ & MES $<1$ \\
\hline Kim et al., 2020 & {$[52]$} & $0.888(0.808 ; 0.943)$ & $0.621(0.423 ; 0.793)$ & MES $\leq 1$ \\
\hline Kristensen et al., 2015 & {$[54]$} & $0.889(0.653 ; 0.986)$ & $0.841(0.699 ; 0.934)$ & MES $<1$ \\
\hline Mak et al., 2018 & [71] & $0.783(0.563 ; 0.925)$ & $0.658(0.486 ; 0.804)$ & MES $\leq 1$ \\
\hline Patel et al., 2017 & [72] & $0.871(0.702 ; 0.964)$ & $0.862(0.683 ; 0.961)$ & MES $\leq 1$ \\
\hline Stevens et al., 2020 (wk 8) & {$[62]$} & $0.770(0.731 ; 0.806)$ & $0.686(0.577 ; 0.782)$ & MES $<1$ \\
\hline Stevens et al., 2020 (wk 52) & [62] & $0.632(0.575 ; 0.686)$ & $0.809(0.667 ; 0.909)$ & MES $\leq 1$ \\
\hline Takashima et al., 2015 & [73] & $0.766(0.656 ; 0.855)$ & $0.733(0.449 ; 0.922)$ & MES $<1$ \\
\hline Yamaguchi et al., 2016 & [65] & $0.670(0.566 ; 0.764)$ & $0.909(0.587 ; 0.998)$ & MES $\leq 1$ \\
\hline Yen et al., 2020 & [66] & $0.742(0.554 ; 0.881)$ & $0.842(0.604 ; 0.966)$ & MES $\overline{\leq} 1$ \\
\hline Chen et al., 2017 & {$[46]$} & $0.833(0.516 ; 0.979)$ & $1.000(0.891 ; 1.000)$ & MES $<2$ \\
\hline Cannatelli et al., 2020 & {$[42]$} & $0.879(0.718 ; 0.966)$ & $0.767(0.614 ; 0.882)$ & $\operatorname{modPICaSSO} \leq 3$ \\
\hline Langhorst et al., 2016 & [74] & $0.108(0.055 ; 0.185)$ & $0.986(0.925 ; 1.000)$ & $\mathrm{RI} \leq 1$ \\
\hline Nancey et al., 2013 & [44] & $0.850(0.621 ; 0.968)$ & $0.914(0.769 ; 0.982)$ & $R I \leq 2$ \\
\hline Önal et al. 2012 & [75] & 0.767 (0.577; 0.901) & $0.800(0.614 ; 0.923)$ & $\mathrm{RI}<4$ \\
\hline Voiosu et al., 2014 & [64] & $0.938(0.698 ; 0.998)$ & $0.500(0.319 ; 0.681)$ & SES-UC $<3$ \\
\hline Theede et al. 2015 & {$[63]$} & $0.781(0.600 ; 0.907)$ & $0.875(0.787 ; 0.936)$ & UCEIS $=0$ \\
\hline Cannatelli et al., 2020 & [42] & $0.939(0.798 ; 0.993)$ & $0.814(0.666 ; 0.916)$ & UCEIS $\leq 1$ \\
\hline Ryu et al., 2019 & [60] & $0.746(0.616 ; 0.850)$ & $0.765(0.677 ; 0.839)$ & UCEIS $<1$ \\
\hline Walsh et al., 2019 & {$[76]$} & $1.000(0.839 ; 1.000)$ & $0.667(0.510 ; 0.800)$ & UCEIS $\leq 1$ \\
\hline Lin et al., 2015 & [33] & $0.875(0.676 ; 0.973)$ & $0.750(0.551 ; 0.893)$ & UCEIS $<3$ \\
\hline \multirow{5}{*}{$\begin{array}{l}\text { Random effects model: } \\
\text { Quantifying heterogeneity: }\end{array}$} & & $0.804(0.757 ; 0.843)$ & $0.817(0.780 ; 0.848)$ & \\
\hline & & & & \\
\hline & & $\operatorname{tau}^{2}=0.6772$ & $\operatorname{tau}^{2}=0.4718$ & \\
\hline & & $I^{2}=87.5 \%$ & $I^{2}=78.6 \%$ & \\
\hline & & $\mathrm{Q}=363.28(<0.0001)$ & $Q=209.42(<0.0001)$ & \\
\hline
\end{tabular}

Figure 4 shows a summary ROC curve (plot of sensitivity against 1-specificity) which was estimated with the use of the bivariate random effects meta-analysis model. The summary ROC curve was generated with 49 studies/applications of FC in the diagnosis of mucosal healing in ulcerative colitis. The summary test sensitivity is 0.783 (95\% CI 
0.738 to 0.822$)$, while the specificity of the use of faecal calprotectin was estimated to be 0.799 (95\% CI 0.769 to 0.829 ). The summary's AUC is 0.858 and the bivariate model-based estimation of DOR $=14.48$. This is less than the estimation based on the univariate random effects model.

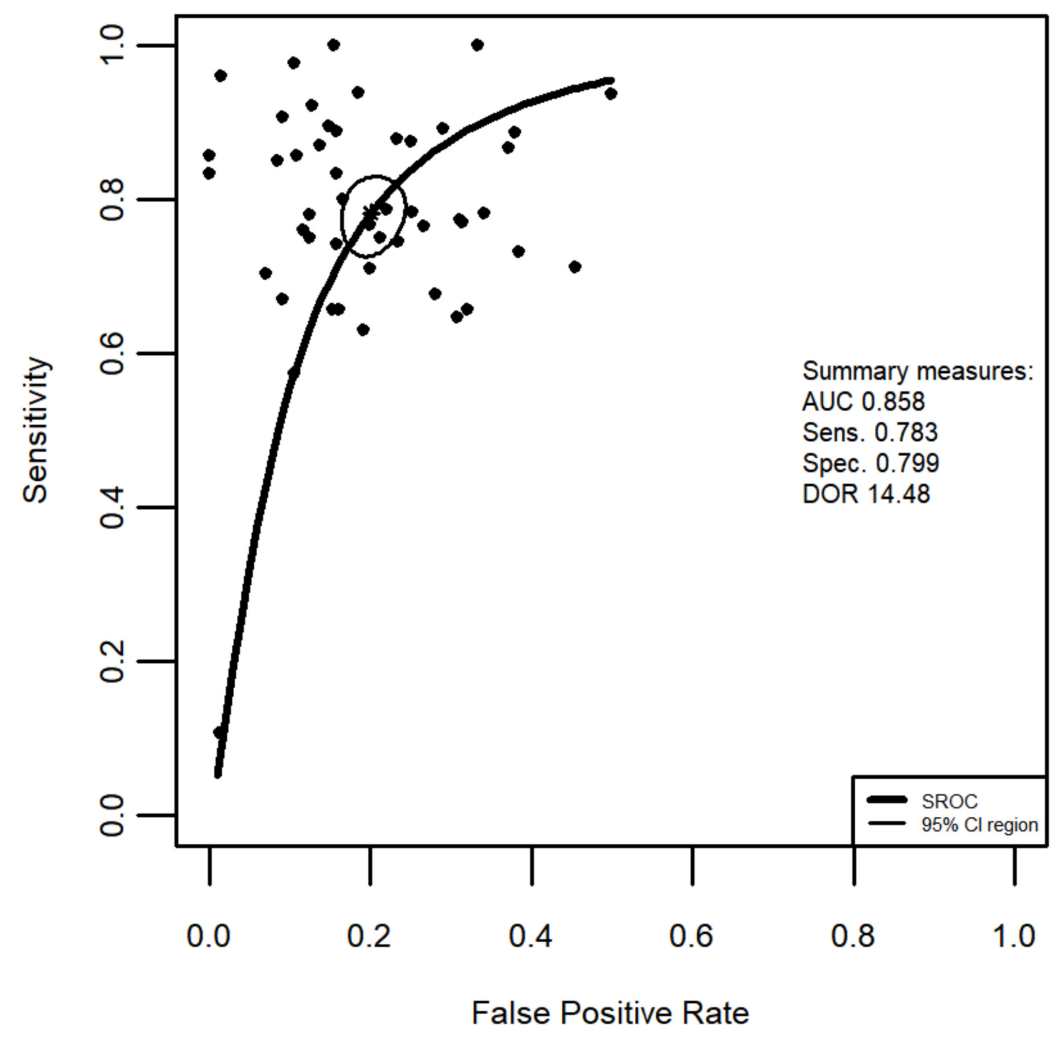

Figure 4. Summary Receiver Operating Characteristic (sROC) curve of the application of FC in the diagnosis of mucosal healing in ulcerative colitis superimposed on Sensitivity and False Positive Rate (1-specificity) results from 49 applications. Summary Sensitivity and summary False Positive Rates are shown as a star, with the $95 \%$ CI area circled. Abbreviations: AUC, area under the curve; Sens., sensitivity; Spec. specificity; DOR, diagnostic odds ratio, CI, confidence interval.

To study possible bias in reporting, a funnel plot of the diagnostic OD against the standard error of the effect estimate was generated (data not shown). Eleven studies out of 49 included in this meta-analysis are found outside the 95\% ( $p$-value 0.05 ) boundaries of the funnel plot. The distribution was skewed towards the studies with a relatively small sample size and high DOR. Four of those are still within the boundaries. Most of the studies lie in the high significance region, suggesting that the asymmetry is not due the publication selection. Studies outside the funnel area: Schoepfers et al. [48], Scaioli et al. [61], Yamaguchi et al. [65], Kostas et al. [53], Nakov et al. [59], Karling et al. [51], Hart et al. [69], and all application studies contained in the publication of Stevens et al. [62].

\section{Discussion}

The diagnostic odds ratio is the main measure for comparison of the diagnostic tests in this meta-analysis. Different though similar results could be observed with the use of two DOR calculation models. The univariate effects model predicts the DOR to be higher than that estimated with the use of the bivariate model based on the Reitsma's method [77]. This is true for the application of FC as the biomarker of MH in both CD and UC. A DOR estimated with either method can be found within a confidence interval of the other. Both DOR values generally represent good diagnostic accuracy of the test. Thus, results of our meta-analysis support the use of faecal calprotectin as a non-invasive biomarker of mucosal healing in IBD. 
The calculated summary DOR of faecal calprotectin-based determination of a patient's mucosal healing status in CD, shows that the odds of a positive result (low faecal calprotectin) among patients with the disease in remission is 13.8 (95\% CI 9.1-20.9) times higher than the odds for positive results among patients with still active inflammation (Figure 1). The Reitsma's model estimates the DOR to be 11.48 (Figure 3). The DOR in the case of FC applied in UC is higher: 16.0 and 14.48 (for univariate and bivariate models, respectively). Only in one study, by Yamaguchi et al. [65], did the estimated DOR's lower boundary of the $95 \%$ confidence interval drop below 1 (Figure 3). This was observed when MES $=0$ was used as the definition of MH. On the other hand, the summary DOR could be artificially elevated/biased due to a high DOR (DOR = 1560), as obtained from the study of Nakov et al. [59]. It is worth noting four applications of FC as a marker of mucosal healing were presented in the publication by Stevens et al. [62]. Authors collected data from hundreds of UC patients participating in a phase 4 trial and performed a post-hoc analysis with two $\mathrm{MH}$ definitions (MES $=0, \mathrm{MES} \leq 1$ ). These were applied to two datasets; endoscopic evaluation of mesalamine treatment at week 8 , and endoscopic evaluation of mesalamine maintenance treatment effects at week 52. Based on these data from Stevens et al. [62], all four individual test DOR values were rather low (between 4.4 and 7.3). In fact, none of the DOR confidence intervals even reached the cumulative value (DOR $=16.0$ ) estimated in this study. This can be interpreted as follows: DOR estimated for tests with larger populations might result in lower values of the summary DOR than estimated here. This notion is supported by our bias analysis; studies with high SE tend to have a higher estimated OR.

The overall good diagnostic test accuracy can be seen from the summary ROC of the FC diagnostic test. In patients with CD the area under the summary ROC covers $82.9 \%$ of the plot area, whereas in patients with UC the area under the $\mathrm{ROC}=85.8 \%$.

One of the issues which limits this meta-analysis is the lack of agreement on the definition of mucosal healing in IBD patients. In our analysis there was no difference of the DOR between studies classified by their MH definition (both for UC and CD; data not shown). The $\mathrm{MH}$ in ulcerative colitis in the compared studies was determined with the use of 6 scales/indices which took 13 different values. The most commonly used was the Mayo Endoscopic Score. It was applied in 37 studies with the majority (24 studies) defining $\mathrm{MH}$ as MES $=0$. In one study it was defined as MES $\leq 2$ [46]. Other MH definitions used were the modified Baron Score $(\mathrm{mBS}=0, \mathrm{mBS} \leq 1)$, the modified PICaSSO $\leq 3$ [42], the Rachmilewitz Index (RI $\leq 1$ [74], RI $\leq 2$ [44], RI $\leq 4$ [75]); the Simple Endoscopic Score for Ulcerative Colitis (SES-UC $\leq 3$ [64]), and the Ulcerative Colitis Endoscopic Index of Severity (UCEIS $=0$ [63], UCEIS $\leq 1$ [42,60,76], UCEIS $\leq 3$ [33]).

In the case of CD in included studies, $\mathrm{MH}$ was defined as SES-CD $=0, \mathrm{SES}-\mathrm{CD} \leq 2$, SES-CD $\leq 3$, as well as CDEIS $<3$, CDEIS $\leq 3$, and CDEIS $<6$ (Table 1 and references therein). SES-CD was the most often used index (total 13 studies). This could be explained by the fact that SES-CD is a simplified, easier to calculate version of CDEIS. Travis et al. performed a validation test in which the SES-CD and CDEIS were compared. Both scores showed a strong positive correlation $(r=0.92)$ [78].

The studies included in this meta-analysis show the wide range of cut-off values (13.9 to $251 \mu \mathrm{g} / \mathrm{g}$ ) which were chosen by authors studying FC as a marker of mucosal healing in ulcerative colitis. The most common thresholds are found between $150-250 \mu \mathrm{g} / \mathrm{g}$ (31/49 studies). Similarly, there was no universal cut-off value for FC in analysed studies on CD. The reported range is very wide: $54-918 \mu \mathrm{g} / \mathrm{g}$ FC, mean cut-off $205 \mu \mathrm{g} / \mathrm{g}$. The cut-off between $150 \mu \mathrm{g} / \mathrm{g}$ and $250 \mu \mathrm{g} / \mathrm{g}$ was used in 7 out of 17 studies. The authors of studies with the extreme cut-off values used different definitions of endoscopic mucosal healing (SES-CD $=0$ and CDEIS $<6$, respectively), as well as applied different types of tests for FC in stool samples (rapid test and ELISA, respectively) [33,38]. According to Moniuszko et al.,rapid FC tests which could be performed at the point-of-care yielded results in high agreement with ELISA-assays [79].

IBD cannot be seen as the exclusive cause of elevated faecal calprotectin. In a study by Meuccion et al., 36\% of patients with normal colonoscopy had elevated FC levels, and the 
marker was elevated in a similar proportion of those with trivial endoscopic findings [80]. Moreover, faecal calprotectin above $50 \mu \mathrm{g} / \mathrm{g}$ has been found in $85 \%$ of patients with colonic cancer, $81 \%$ of those with "inflammatory conditions" (active CD or in remission, active UC, ischaemic colon), and 50\% of those with UC in remission [80]. Furthermore, common medications are associated with increased FC. Lundgren et al. observed that among patients with a normal colonoscopy, FC above $50 \mu \mathrm{g} / \mathrm{g}$ was shown for $55 \%$ patients using acetylsalicylic acid, $24 \%$ using non-steroidal anti-inflammatory drugs, and $52 \%$ treated with proton pump inhibitors [81]. On the other hand, a recent multicenter study on pregnant women concluded that physiological changes due to pregnancy do not affect FC levels [82]. Therefore, Julsgaard et al. suggested the use of FC in the monitoring of IBD during pregnancy [82]. The lack of a universal FC cut-off is one of the biggest limitations of the use of this biomarker in either UC or CD. The issue has several factors influencing it: the methodological and technical differences between FC assays, the MH definition applied by physicians, and inter-individual variability in FC values. As for the latter, a potential explanation for the wide ranges in reporting cut-off values might be residual inflammation that may still remain at a microscopic (histologic; neutrophiles infiltrating the mucosa) level despite the remission and mucosal healing being reported by an endoscopist.

The following limitations of this meta-analysis should be taken in consideration. Firstly, due to apparent fluctuations of cut-off values for FC in analysed studies, this meta-analysis could not provide a clinical recommendation on one definite FC cut-off value which could help in the assessment of IBD activity without an endoscopy. Secondly, obvious heterogeneity existed across the included studies. The different MH definitions, methodological differences between FC assays, as well as sizes of tested populations might be the sources of heterogeneity in the meta-analysis.

\section{Conclusions}

In the light of the obtained results, a positive answer to the main question of the meta-analysis can be given. The DOR for the use of FC in CD is estimated to be 11.20. In the case of UC, the DOR is 14.48. The bivariate model applied to the estimation of sensitivity of FC in the detection of mucosal healing resulted in the summary sensitivity of 0.807 and 0.783 for CD and UC, respectively. Despite good sensitivity and specificity of the FC test in the determination of IBD activity, we suggest caution in clinical decisionmaking on a single FC result. Nevertheless, FC is the most widely used and the most supported tool in the assessment of mucosal healing in UC and CD without the need for endoscopy. The odds of confirming mucosal healing with a non-invasive FC test support their further use in the management of IBD. We recommend that future studies reporting on the topic should include data (e.g., contingency tables) for various cut-off values. Further research into the establishment of a universal cut-off for FC should accompany work into the interchangeability of FC diagnostic tests.

Supplementary Materials: The following are available online at https:/ /www.mdpi.com/article/ 10.3390/jcm10102203/s1, Figure S1: Flow diagram of data selection; Table S1: Meta-analysis data; Table S2: PRISMA 2009 Checklist.

Author Contributions: Conceptualisation, M.A.B. and M.K.-K.; methodology, M.A.B.; data acquisition, R.K., M.A.B.; data curation, R.K., K.N., M.K.-K.; data analysis, M.A.B., writing-original draft preparation, M.A.B.; writing—review and editing, M.K.-K., R.K., K.N.; supervision, M.K.-K. All authors have read and agreed to the published version of the manuscript.

Funding: This research received no external funding.

Institutional Review Board Statement: Not applicable.

Informed Consent Statement: Not applicable.

Data Availability Statement: Data used in this meta-analysis are contained in Supplementary Materials.

Conflicts of Interest: The authors declare no conflict of interest. 


\section{References}

1. Colombel, J.F.; Mahadevan, U. Inflammatory Bowel Disease 2017: Innovations and Changing Paradigms. Gastroenterology 2017, 152, 309-312. [CrossRef] [PubMed]

2. De Souza, H.S.P.; Fiocchi, C. Network Medicine: A Mandatory Next Step for Inflammatory Bowel Disease. Inflamm. Bowel Dis. 2018, 4, 671-679. [CrossRef]

3. Vavricka, S.R.; Schoepfer, A.; Scharl, M.; Lakatos, P.L.; Navarini, A.; Rogler, G. Extraintestinal Manifestations of Inflammatory Bowel Disease. Inflamm. Bowel Dis. 2015, 21, 1982-1992. [CrossRef]

4. Colombel, J.-F.; D’haens, G.; Lee, W.-J.; Petersson, J.; Panaccione, R. Outcomes and Strategies to Support a Treat-to-target Approach in Inflammatory Bowel Disease: A Systematic Review. J. Crohn's Colitis 2020, 14, 254-266. [CrossRef] [PubMed]

5. Peyrin-Biroulet, L.; Sandborn, W.; Sands, B.E.; Reinisch, W.; Bemelman, W.; Bryant, R.V.; D’Haens, G.; Dotan, I.; Dubinsky, M.; Feagan, B.; et al. Selecting Therapeutic Targets in Inflammatory Bowel Disease (STRIDE): Determining Therapeutic Goals for Treat-to-Target. Am. J. Gastroenterol. 2015, 110, 1324-1338. [CrossRef] [PubMed]

6. Magro, F.; Gionchetti, P.; Eliakim, R.; Ardizzone, S.; Armuzzi, A.; Barreiro-de Acosta, M.; Burisch, J.; Gecse, K.; Hart, A.; Hindryckx, P.; et al. Third European Evidence-based Consensus on Diagnosis and Management of Ulcerative Colitis. Part 1: Definitions, Diagnosis, Extra-intestinal Manifestations, Pregnancy, Cancer Surveillance, Surgery, and Ileo-anal Pouch Disorders. J. Crohn's Colitis 2017, 11, 649-670. [CrossRef] [PubMed]

7. Sandborn, W.J.; Colombel, J.-F.; Panaccione, R.; Dulai, P.S.; Rosario, M.; Cao, C.; Barocas, M.; Lasch, K. Deep Remission with Vedolizumab in Patients with Moderately to Severely Active Ulcerative Colitis: A GEMINI 1 post hoc Analysis. J. Crohn's Colitis 2019, 13, 172-181. [CrossRef]

8. Schroeder, K.W.; Tremaine, W.J.; Ilstrup, D.M. Coated Oral 5-Aminosalicylic Acid Therapy for Mildly to Moderately Active Ulcerative Colitis. N. Engl. J. Med. 1987, 17, 1625-1629. [CrossRef]

9. Rutgeerts, P.; Sandborn, W.J.; Feagan, B.G.; Reinisch, W.; Olson, A.; Johanns, J.; Travers, S.; Rachmilewitz, D.; Hanauer, S.B.; Lichtenstein, G.R.; et al. Infliximab for induction and maintenance therapy for ulcerative colitis. N. Engl. J. Med. 2005, 53, 2462-2476. [CrossRef]

10. Maaser, C.; Sturm, A.; Vavricka, S.R.; Kucharzik, T.; Fiorino, G.; Annese, V.; Calabrese, E.; Baumgart, D.C.; Bettenworth, D.; Borralho Nunes, P.; et al. ECCO-ESGAR Guideline for Diagnostic Assessment in IBD Part 1: Initial diagnosis, monitoring of known IBD, detection of complications. J. Crohn's Colitis 2019, 13, 144-164K. [CrossRef] [PubMed]

11. Sturm, A.; Maaser, C.; Calabrese, E.; Annese, V.; Fiorino, G.; Kucharzik, T.; Vavricka, S.R.; Verstockt, B.; Van Rheenen, P.; Tolan, D.; et al. ECCO-ESGAR guideline for diagnostic assessment in ibd part 2: IBD scores and general principles and technical aspects. J. Crohn's Colitis 2019, 13, 273-284. [CrossRef] [PubMed]

12. Matsuoka, K.; Kobayashi, T.; Ueno, F.; Matsui, T.; Hirai, F.; Inoue, N.; Kato, J.; Kobayashi, K.; Kobayashi, K.; Koganei, K.; et al. Evidence-based clinical practice guidelines for inflammatory bowel disease. J. Gastroenterol. 2018, 53, 305-353. [CrossRef]

13. Annese, V.; Daperno, M.; Rutter, M.D.; Amiot, A.; Bossuyt, P.; East, J.; Ferrante, M.; Götz, M.; Katsanos, K.H.; Kießlich, R.; et al. European evidence based consensus for endoscopy in inflammatory bowel disease. J. Crohn's Colitis 2013, 7, 982-1018. [CrossRef] [PubMed]

14. Daperno, M.; D’Haens, G.; Van Assche, G.; Baert, F.; Bulois, P.; Maunoury, V.; Sostegni, R.; Rocca, R.; Pera, A.; Gevers, A.; et al. Development and validation of a new, simplified endoscopic activity score for Crohn's disease: The SES-CD. Gastrointest. Endosc. 2004, 60, 505-512. [CrossRef]

15. Ardizzone, S.; Cassinotti, A.; Duca, P.; Mazzali, C.; Penati, C.; Manes, G.; Marmo, R.; Massari, A.; Molteni, P.; Maconi, G.; et al. Mucosal Healing Predicts Late Outcomes After the First Course of Corticosteroids for Newly Diagnosed Ulcerative Colitis. Clin. Gastroenterol. Hepatol. 2011, 9, 483-489. [CrossRef]

16. Colombel, J.F.; Rutgeerts, P.; Reinisch, W.; Esser, D.; Wang, Y.; Lang, Y.; Marano, C.W.; Strauss, R.; Oddens, B.J.; Feagan, B.G.; et al. Early mucosal healing with infliximab is associated with improved long-term clinical outcomes in ulcerative colitis. Gastroenterology 2011, 141, 1194-1201. [CrossRef]

17. Rutter, M.; Saunders, B.; Wilkinson, K.; Rumbles, S.; Schofield, G.; Kamm, M.; Williams, C.; Price, A.; Talbot, I.; Forbes, A. Severity of inflammation is a risk factor for colorectal neoplasia in ulcerative colitis. Gastroenterology 2004, 126, 451-459. [CrossRef] [PubMed]

18. Rutter, M.D.; Saunders, B.P.; Wilkinson, K.H.; Rumbles, S.; Schofield, G.; Kamm, M.A.; Williams, C.B.; Price, A.B.; Talbot, I.C.; Forbes, A. Cancer surveillance in longstanding ulcerative colitis: Endoscopic appearances help predict cancer risk. Gut 2004, 53, 1813-1816. [CrossRef]

19. Frøslie, K.F.; Jahnsen, J.; Moum, B.A.; Vatn, M.H. Mucosal Healing in Inflammatory Bowel Disease: Results From a Norwegian Population-Based Cohort. Gastroenterology 2007, 133, 412-422. [CrossRef]

20. Shah, S.C.; Colombel, J.F.; Sands, B.E.; Narula, N. Systematic review with meta-analysis: Mucosal healing is associated with improved long-term outcomes in Crohn's disease. Aliment. Pharmacol. Ther. 2016, 43, 317-333. [CrossRef]

21. Reinink, A.R.; Lee, T.C.; Higgins, P.D.R. Endoscopic Mucosal Healing Predicts Favorable Clinical Outcomes in Inflammatory Bowel Disease: A Meta-analysis. Inflamm. Bowel Dis. 2016, 22, 1859-1869. [CrossRef]

22. Levartovsky, A.; Ungar, B.; Yavzori, M.; Picard, O.; Fudim, E.; Eliakim, R.; Paul, S.; Roblin, X.; Ben-Horin, S.; Kopylov, U. Infliximab levels and antibodies in IBD-related peripheral arthralgia. Int. J. Colorectal Dis. 2020, 35, 1141-1148. [CrossRef] 
23. Mancina, R.M.; Pagnotta, R.; Pagliuso, C.; Albi, V.; Bruno, D.; Garieri, P.; Doldo, P.; Spagnuolo, R. Gastrointestinal Symptoms of and Psychosocial Changes in Inflammatory Bowel Disease: A Nursing-Led Cross-Sectional Study of Patients in Clinical Remission. Medicina 2020, 56, 45. [CrossRef] [PubMed]

24. Mak, W.Y.; Zhao, M.; Ng, S.C.; Burisch, J. The epidemiology of inflammatory bowel disease: East meets west. J. Gastroenterol. Hepatol. 2020, 35, 380-389. [CrossRef]

25. Occhipinti, V.; Pastorelli, L. Challenges in the Care of IBD Patients During the CoViD-19 Pandemic: Report From a "Red Zone" Area in Northern Italy. Inflamm. Bowel Dis. 2020, 26, 793-796. [CrossRef] [PubMed]

26. Gonzalez, H.A.; Myers, S.; Whitehead, E.; Pattinson, A.; Stamp, K.; Turnbull, J.; Fory, R.; Featherstone, B.; Wilkinson, A.; Lisle, J.; et al. React, reset and restore: Adaptation of a large inflammatory bowel disease service during COVID-19 pandemic. Clin. Med. 2020, 20, e183-e188. [CrossRef] [PubMed]

27. Spagnuolo, R.; Larussa, T.; Iannelli, C.; Cosco, C.; Nisticò, E.; Manduci, E.; Bruno, A.; Boccuto, L.; Abenavoli, L.; Luzza, F.; et al. COVID-19 and Inflammatory Bowel Disease: Patient Knowledge and Perceptions in a Single Center Survey. Medicina 2020, 56, 407. [CrossRef]

28. Krzystek-Korpacka, M.; Kempiński, R.; Bromke, M.; Neubauer, K. Biochemical Biomarkers of Mucosal Healing for Inflammatory Bowel Disease in Adults. Diagnostics 2020, 10, 367. [CrossRef]

29. Voganatsi, A.; Panyutich, A.; Miyasaki, K.T.; Murthy, R.K. Mechanism of extracellular release of human neutrophil calprotectin complex. J. Leukoc. Biol. 2001, 70, 130-134. [CrossRef]

30. Naess-Andresen, C.F.; Egelandsdal, B.; Fagerhol, M.K. Calcium binding and concomitant changes in the structure and heat stability of calprotectin (L1 protein). Clin. Mol. Pathol. 1995, 48, M278-M284. [CrossRef] [PubMed]

31. Moher, D.; Liberati, A.; Tetzlaff, J.; Altman, D.G. Preferred Reporting Items for Systematic Reviews and Meta-Analyses: The PRISMA Statement. Ann. Intern. Med. 2009, 151, 264-269. [CrossRef]

32. Karczewski, J.; Swora-Cwynar, E.; Rzymski, P.; Poniedziałek, B.; Adamski, Z. Selected biologic markers of inflammation and activity of Crohn's disease. Autoimmunity 2015, 48, 318-327. [CrossRef]

33. Lin, W.-C.; Wong, J.-M.; Tung, C.-C.; Lin, C.-P.; Chou, J.-W.; Wang, H.-Y.; Shieh, M.-J.; Chang, C.-H.; Liu, H.-H.; Wei, S.-C.; et al. Fecal calprotectin correlated with endoscopic remission for Asian inflammatory bowel disease patients. World J. Gastroenterol. 2015, 21, 13566-13573. [CrossRef] [PubMed]

34. Lobatón, T.; López-García, A.; Rodríguez-Moranta, F.; Ruiz, A.; Rodríguez, L.; Guardiola, J. A new rapid test for fecal calprotectin predicts endoscopic remission and postoperative recurrence in Crohn's disease. J. Crohn's Colitis 2013, 7, e641-e651. [CrossRef]

35. Reinisch, W.; Panaccione, R.; Bossuyt, P.; Baert, F.; Armuzzi, A.; Hébuterne, X.; Travis, S.; Danese, S.; Sandborn, W.J.; Schreiber, S.; et al. Association of Biomarker Cutoffs and Endoscopic Outcomes in Crohn's Disease: A Post Hoc Analysis from the CALM Study. Inflamm. Bowel Dis. 2020, 26, 1562-1571. [CrossRef]

36. Inokuchi, T.; Kato, J.; Hiraoka, S.; Takashima, S.; Nakarai, A.; Takei, D.; Sugihara, Y.; Takahara, M.; Kawano, S.; Harada, K.; et al. Fecal Immunochemical Test Versus Fecal Calprotectin for Prediction of Mucosal Healing in Crohn's Disease. Inflamm. Bowel Dis. 2016, 22, 1078-1085. [CrossRef] [PubMed]

37. Iwamoto, F.; Matsuoka, K.; Motobayashi, M.; Takenaka, K.; Kuno, T.; Tanaka, K.; Tsukui, Y.; Kobayashi, S.; Yoshida, T.; Fujii, T.; et al. Prediction of disease activity of Crohn's disease through fecal calprotectin evaluated by balloon-assisted endoscopy. J. Gastroenterol. Hepatol. 2018, 33, 1984-1989. [CrossRef] [PubMed]

38. Jusué, V.; Chaparro, M.; Gisbert, J.P. Accuracy of fecal calprotectin for the prediction of endoscopic activity in patients with inflammatory bowel disease. Dig. Liver Dis. 2018, 50, 353-359. [CrossRef] [PubMed]

39. Lopes, S.; Andrade, P.; Afonso, J.; Cunha, R.; Rodrigues-Pinto, E.; Ramos, I.; Macedo, G.; Magro, F. Monitoring Crohn's disease activity: Endoscopy, fecalmarkers and computed tomography enterography. Therap. Adv. Gastroenterol. 2018, 11, e175628481876907. [CrossRef]

40. AfBjörkesten, C.G.; Nieminen, U.; Turunen, U.; Arkkila, P.; Sipponen, T.; Frkkil, M. Surrogate markers and clinical indices, alone or combined, as indicators for endoscopic remission in anti-TNF-treated luminal Crohn's disease. Scand. J. Gastroenterol. 2012, 47, 528-537. [CrossRef]

41. E Penna, F.G.C.; Rosa, R.M.; da Cunha, P.F.S.; de Souza, S.C.S.; de Abreu Ferrari, M.D.L. Faecal calprotectin is the biomarker that best distinguishes remission from different degrees of endoscopic activity in Crohn's disease. BMC Gastroenterol. $2020,20,35$. [CrossRef]

42. Cannatelli, R.; Bazarova, A.; Zardo, D.; Nardone, O.M.; Shivaji, U.; Smith, S.C.L.; Gkoutos, G.; Ricci, C.; Gui, X.S.; Ghosh, S.; et al. Fecal Calprotectin Thresholds to Predict Endoscopic Remission Using Advanced Optical Enhancement Techniques and Histological Remission in IBD Patients. Inflamm. Bowel Dis. 2020, 27, 647-654. [CrossRef] [PubMed]

43. Falvey, J.D.; Hoskin, T.; Meijer, B.; Ashcroft, A.; Walmsley, R.; Day, A.S.; Gearry, R.B. Disease activity assessment in IBD: Clinical indices and biomarkers fail to predict endoscopic remission. Inflamm. Bowel Dis. 2015, 21, 824-831. [CrossRef]

44. Nancey, S.; Boschetti, G.; Moussata, D.; Cotte, E.; Peyras, J.; Cuerq, C.; Haybrard, J.; Charlois, A.-L.; Mialon, A.; Chauvenet, M.; et al. Neopterin Is a Novel Reliable Fecal Marker as Accurate as Calprotectin for Predicting Endoscopic Disease Activity in Patients with Inflammatory Bowel Diseases. Inflamm. Bowel Dis. 2013, 19, 1043-1052. [CrossRef]

45. Vázquez-Morón, J.M.; Pallarés-Manrique, H.; Machancoses, F.H.; Ramos-Lora, M.; Ruiz-Frutos, C. Accurate cut-offs for predicting endoscopic activity and mucosal healing in Crohn's disease with fecal calprotectin. Rev. Española Enfermedades Dig. 2017, 109, 130-136. [CrossRef] 
46. Chen, J.M.; Liu, T.; Gao, S.; Tong, X.D.; Deng, F.H.; Nie, B. Efficacy of noninvasive evaluations in monitoring inflammatory bowel disease activity: A prospective study in China. World J. Gastroenterol. 2017, 23, 8235-8247. [CrossRef] [PubMed]

47. Schaffer, T.; Schoepfer, A.M.; Seibold, F. Serum ficolin-2 correlates worse than fecal calprotectin and CRP with endoscopic Crohn's disease activity. J. Crohn's Colitis 2014, 8, 1125-1132. [CrossRef] [PubMed]

48. Schoepfer, A.M.; Beglinger, C.; Straumann, A.; Safroneeva, E.; Romero, Y.; Armstrong, D.; Schmidt, C.; Trummler, M.; Pittet, V.; Vavricka, S.R. Fecal Calprotectin More Accurately Reflects Endoscopic Activity of Ulcerative Colitis than the Lichtiger Index, C-reactive Protein, Platelets, Hemoglobin, and Blood Leukocytes. Inflamm. Bowel Dis. 2013, 19, 332-341. [CrossRef] [PubMed]

49. Carlsen, K.; Riis, L.B.; Elsberg, H.; Maagaard, L.; Thorkilgaard, T.; Sørbye, S.W.; Jakobsen, C.; Wewer, V.; Florholmen, J.; Goll, R.; et al. The sensitivity of fecal calprotectin in predicting deep remission in ulcerative colitis. Scand. J. Gastroenterol. 2018, 53, 825-830. [CrossRef]

50. Hiraoka, S.; Takashima, S.; Inokuchi, T.; Nakarai, A.; Takahara, M.; Harada, K.; Seki, Y.; Watanabe, K.; Kato, J.; Okada, H. The novel latex agglutination turbidimetric immunoassay system for simultaneous measurements of calprotectin and hemoglobin in feces. Intest. Res. 2019, 17, 202-209. [CrossRef]

51. Karling, P.; Lundgren, D.; Eklöf, V.; Palmqvist, R.; Hultdin, J. Improved monitoring of inflammatory activity in patients with ulcerative colitis by combination of faecal tests for haemoglobin and calprotectin. Scand. J. Clin. Lab. Investig. 2019, 79, 341-346. [CrossRef]

52. Kim, E.S.; Lee, H.S.; Kim, S.K.; Kim, E.Y.; Jang, B.I.; Kim, K.O.; Yang, C.H.; Lee, Y.J. Fecal calprotectin is more accurate than fecal immunochemical test for predicting mucosal healing in quiescent ulcerative colitis: A prospective multicenter study. Scand. J. Gastroenterol. 2020, 55, 163-168. [CrossRef]

53. Kostas, A.; Siakavellas, S.I.; Kosmidis, C.; Takou, A.; Nikou, J.; Maropoulos, G.; Vlachogiannakos, J.; Papatheodoridis, G.V.; Papaconstantinou, I.; Bamias, G. Fecal calprotectin measurement is a marker of short-term clinical outcome and presence of mucosal healing in patients with inflammatory bowel disease. World J. Gastroenterol. 2017, 23, 7387-7396. [CrossRef]

54. Kristensen, V.; Klepp, P.; Cvancarova, M.; Roseth, A.; Skar, V.; Moum, B. Prediction of Endoscopic Disease Activity in Ulcerative Colitis by Two Different Assays for Fecal Calprotectin. J. Crohn's Colitis 2015, 9, 164-169. [CrossRef]

55. Lee, S.-H.; Kim, M.-J.; Chang, K.; Song, E.M.; Hwang, S.W.; Park, S.H.; Yang, D.-H.; Kim, K.-J.; Byeon, J.-S.; Myung, S.-J.; et al. Fecal calprotectin predicts complete mucosal healing and better correlates with the ulcerative colitis endoscopic index of severity than with the Mayo endoscopic subscore in patients with ulcerative colitis. BMC Gastroenterol. 2017, 17, 110. [CrossRef] [PubMed]

56. Lee, Y.W.; Lee, K.-M.; Lee, J.M.; Chung, Y.Y.; Kim, D.B.; Kim, Y.J.; Chung, W.C.; Paik, C.-N. The usefulness of fecal calprotectin in assessing inflammatory bowel disease activity. Korean J. Intern. Med. 2019, 34, 72-80. [CrossRef] [PubMed]

57. Lobatón, T.; Rodríguez-Moranta, F.; Lopez, A.; Sánchez, E.; Rodríguez-Alonso, L.; Guardiola, J. A New Rapid Quantitative Test for Fecal Calprotectin Predicts Endoscopic Activity in Ulcerative Colitis. Inflamm. Bowel Dis. 2013, 19, 1034-1042. [CrossRef]

58. Mine, S.; Takeshima, F.; Akazawa, Y.; Matsushima, K.; Minami, H.; Yamaguchi, N.; Ohnita, K.; Isomoto, H.; Nakao, K. Correlation of Fecal Markers with Magnifying Endoscopic Stratification in Patients with Ulcerative Colitis Who Are in Clinical Remission. Digestion 2018, 97, 82-89. [CrossRef]

59. Nakov, R.; Velikova, T.; Nakov, V.; Ianiro, G.; Gerova, V.; Tankova, L. Serum trefoil factor 3 predicts disease activity in patients with ulcerative colitis. Eur. Rev. Med. Pharmacol. Sci. 2019, 23, 788-794. [CrossRef] [PubMed]

60. Ryu, D.G.; Kim, H.W.; Park, S.B.; Kang, D.H.; Choi, C.W.; Kim, S.J.; Nam, H.S. Clinical implications of fecal calprotectin and fecal immunochemical test on mucosal status in patients with ulcerative colitis. Medicine 2019, 98, e17080. [CrossRef] [PubMed]

61. Scaioli, E.; Scagliarini, M.; Cardamone, C.; Liverani, E.; Ugolini, G.; Festi, D.; Bazzoli, F.; Belluzzi, A. Clinical application of faecal calprotectin in ulcerative colitis patients. Eur. J. Gastroenterol. Hepatol. 2015, 27, 1418-1424. [CrossRef] [PubMed]

62. Stevens, T.W.; Gecse, K.; Turner, J.R.; de Hertogh, G.; Rubin, D.T.; D'Haens, G.R. Diagnostic Accuracy of Fecal Calprotectin Concentration in Evaluating Therapeutic Outcomes of Patients with Ulcerative Colitis. Clin. Gastroenterol. Hepatol. 2020, in press. [CrossRef] [PubMed]

63. Theede, K.; Holck, S.; Ibsen, P.; Ladelund, S.; Nordgaard-Lassen, I.; Nielsen, A.M. Level of Fecal Calprotectin Correlates with Endoscopic and Histologic Inflammation and Identifies Patients With Mucosal Healing in Ulcerative Colitis. Clin. Gastroenterol. Hepatol. 2015, 13, 1929-1936.e1. [CrossRef]

64. Voiosu, T.; Benguş, A.; Dinu, R.; Voiosu, A.M.; Bălănescu, P.; Băicuş, C.; Diculescu, M.; Voiosu, R.; Mateescu, B. Rapid fecal calprotectin level assessment and the SIBDQ score can accurately detect active mucosal inflammation in IBD patients in clinical remission: A prospective study. J. Gastrointest. Liver Dis. 2014, 23, 273-278. [CrossRef] [PubMed]

65. Yamaguchi, S.; Takeuchi, Y.; Arai, K.; Fukuda, K.; Kuroki, Y.; Asonuma, K.; Takahashi, H.; Saruta, M.; Yoshida, H. Fecal calprotectin is a clinically relevant biomarker of mucosal healing in patients with quiescent ulcerative colitis. J. Gastroenterol. Hepatol. 2016, 31, 93-98. [CrossRef] [PubMed]

66. Yen, H.-H.; Chen, M.-W.; Chang, Y.-Y.; Huang, H.-Y.; Hsu, T.-C.; Chen, Y.-Y. Predictive values of stool-based tests for mucosal healing among Taiwanese patients with ulcerative colitis: A retrospective cohort analysis. PeerJ 2020, 8, e9537. [CrossRef]

67. Zittan, E.; Kelly, O.B.; Kirsch, R.; Milgrom, R.; Burns, J.; Nguyen, G.C.; Croitoru, K.; Van Assche, G.; Silverberg, M.S.; Steinhart, A.H. Low Fecal Calprotectin Correlates with Histological Remission and Mucosal Healing in Ulcerative Colitis and Colonic Crohn's Disease. Inflamm. Bowel Dis. 2016, 22, 623-630. [CrossRef] 
68. Bertani, L.; Blandizzi, C.; Mumolo, M.G.; Ceccarelli, L.; Albano, E.; Tapete, G.; BaianoSvizzero, G.; Zanzi, F.; Coppini, F.; de Bortoli, N.; et al. Fecal Calprotectin Predicts Mucosal Healing in Patients With Ulcerative Colitis Treated With Biological Therapies: A Prospective Study. Clin. Transl. Gastroenterol. 2020, 11, e00174. [CrossRef]

69. Hart, L.; Chavannes, M.; Kherad, O.; Maedler, C.; Mourad, N.; Marcus, V.; Afif, W.; Bitton, A.; Lakatos, P.L.; Brassard, P.; et al. Faecal Calprotectin Predicts Endoscopic and Histological Activity in Clinically Quiescent Ulcerative Colitis. J. Crohn's Colitis 2020, 14, 46-52. [CrossRef] [PubMed]

70. Jha, A.K.; Chaudhary, M.; Dayal, V.M.; Kumar, A.; Jha, S.K.; Jha, P.; Purkayastha, S.; Ranjan, R. Optimal cut-off value of fecal calprotectin for the evaluation of ulcerative colitis: An unsolved issue? JGH Open 2018, 2, 207-213. [CrossRef] [PubMed]

71. Mak, W.Y.; Buisson, A.; Andersen, M.J.; Lei, D.; Pekow, J.; Cohen, R.D.; Kahn, S.A.; Pereira, B.; Rubin, D.T. Fecal Calprotectin in Assessing Endoscopic and Histological Remission in Patients with Ulcerative Colitis. Dig. Dis. Sci. 2018, 63, $1294-1301$. [CrossRef] [PubMed]

72. Patel, A.; Panchal, H.; Dubinsky, M.C. Fecal Calprotectin Levels Predict Histological Healing in Ulcerative Colitis. Inflamm. Bowel Dis. 2017, 23, 1600-1604. [CrossRef]

73. Takashima, S.; Kato, J.; Hiraoka, S.; Nakarai, A.; Takei, D.; Inokuchi, T.; Sugihara, Y.; Takahara, M.; Harada, K.; Okada, H.; et al. Evaluation of Mucosal Healing in Ulcerative Colitis by Fecal Calprotectin Vs. Fecal Immunochemical Test. Am. J. Gastroenterol. 2015, 110, 873-880. [CrossRef]

74. Langhorst, J.; Boone, J.; Lauche, R.; Rueffer, A.; Dobos, G. Faecal Lactoferrin, Calprotectin, PMN-elastase, CRP, and White Blood Cell Count as Indicators for Mucosal Healing and Clinical Course of Disease in Patients with Mild to Moderate Ulcerative Colitis: Post Hoc Analysis of a Prospective Clinical Trial. J. Crohn's Colitis 2016, 10, 786-794. [CrossRef] [PubMed]

75. Onal, I.K.; Beyazit, Y.; Sener, B.; Savuk, B.; Ozer Etik, D.; Sayilir, A.; Oztas, E.; Torun, S.; OzderinOzin, Y.; TuncDemirel, B.; et al. The value of fecal calprotectin as a marker of intestinal inflammation in patients with ulcerative colitis. Turkish J. Gastroenterol. 2012, 23, 509-514. [CrossRef] [PubMed]

76. Walsh, A.; Kormilitzin, A.; Hinds, C.; Sexton, V.; Brain, O.; Keshav, S.; Uhlig, H.; Geddes, J.; Goodwin, G.; Peters, M.; et al. Defining Faecal Calprotectin Thresholds as a Surrogate for Endoscopic and Histological Disease Activity in Ulcerative Colitis-A Prospective Analysis. J. Crohn's Colitis 2019, 13, 424-430. [CrossRef] [PubMed]

77. Reitsma, J.B.; Glas, A.S.; Rutjes, A.W.S.; Scholten, R.J.P.M.; Bossuyt, P.M.; Zwinderman, A.H. Bivariate analysis of sensitivity and specificity produces informative summary measures in diagnostic reviews. J. Clin. Epidemiol. 2005, 58, 982-990. [CrossRef]

78. Travis, S.P.L.; Schnell, D.; Krzeski, P.; Abreu, M.T.; Altman, D.G.; Colombel, J.; Feagan, B.G.; Hanauer, S.B.; Lichtenstein, G.R.; Marteau, P.R.; et al. Reliability and Initial Validation of the Ulcerative Colitis Endoscopic Index of Severity. Gastroenterology 2013, 145, 987-995. [CrossRef]

79. Moniuszko, A.; Głuszek, S.; Rydzewska, G. Does the rapid fecal calprotectin test equally predict mucosal inflammation in both ulcerative colitis (UC) and Crohn's disease (CD)? A prospective analysis of an IBD cohort. Pol. Arch. Intern. Med. 2017, 127, 312-318. [CrossRef]

80. Meucci, G.; D'Incà, R.; Maieron, R.; Orzes, N.; Vecchi, M.; Visentini, D.; Minoli, G.; Dal Pont, E.; Zilli, M.; Benedetti, E.; et al. Diagnostic value of faecal calprotectin in unselected outpatients referred for colonoscopy: A multicenter prospective study. Dig. Liver Dis. 2010, 42, 191-195. [CrossRef]

81. Lundgren, D.; Eklöf, V.; Palmqvist, R.; Hultdin, J.; Karling, P. Proton pump inhibitor use is associated with elevated faecal calprotectin levels. A cross-sectional study on subjects referred for colonoscopy. Scand. J. Gastroenterol. 2019, 54, 152-157. [CrossRef] [PubMed]

82. Julsgaard, M.; Hvas, C.L.; Gearry, R.B.; Vestergaard, T.; Fallingborg, J.; Svenningsen, L.; Kjeldsen, J.; Sparrow, M.P.; Wildt, S.; Kelsen, J.; et al. Fecal Calprotectin Is Not Affected by Pregnancy. Inflamm. Bowel Dis. 2017, 23, 1240-1246. [CrossRef] [PubMed] 